\title{
A Grounded Theory of Veterans' Experiences of Addiction-as-Occupation
}

\author{
Sally Wasmuth, Ph.D, OTR ${ }^{1}$ \\ Richard A. Brandon-Friedman, MSW, LCSW, LCAC ${ }^{2}$ \\ Kyle Olesek, PsyD ${ }^{3}$
}

${ }^{1}$ Associated Health Research Fellow, Richard L. Roudebush VA Medical Center
${ }^{2}$ Doctoral Student, Indiana University School of Social Work
${ }^{3}$ Psychologist, Richard L. Roudebush Domiciliary

This is the author's manuscript of the article published in final edited form as:

Wasmuth, S., Brandon-Friedman, R. A., \& Olesek, K. (2016). A grounded theory of veterans' experiences of addiction-as-occupation. Journal of Occupational Science, 23(1), 128-141. https://doi.org/10.1080/14427591.2015.1070782 


\begin{abstract}
This study examined how addiction emerges as an occupation in the lives of veterans. Its purpose was to facilitate better knowledge of how addiction is experienced as an occupation by this population, with the goal of destigmatizing addiction and paving the way for innovative ways to help people with addictions to build new occupational lives. Fifty-eight veterans diagnosed with a substance use disorder were recruited from a VA residential treatment center, of which 35 transcripts of the Indiana Psychiatric Illness Interview - a broad interview inquiring about participants' life experiences_-were randomly selected for grounded theory analysis following a 4-step coding procedure as outlined by Charmaz. Data revealed a five-step occupational process: Being Initiated; Increasing Engagement; Establishing an Identity; Experiencing Discord and Defeat; and Finding Other Occupations. Addiction is discussed as a behavioral pattern, and the authors discuss how the use of new occupations may provide individuals with new patterns of organization, social interconnection, and identity development needed to sustain a move away from occupations of addiction.
\end{abstract}

KEYWORDS: Substance use disorder, Mental health, Grounded theory, Recovery, Veteran 


\section{A Grounded Theory of Veterans' Experiences of Addiction-as-Occupation}

Occupations have been defined as those things that human beings do to occupy themselves within various contexts (Townsend, 1997). Occupations give meaning to life, organize behavior, shape and are shaped by environments, develop and change over a lifetime, and influence who people are and how they feel about themselves (Canadian Association of Occupational Therapists, 2014). Reflecting these as well as Kielhofner's (2008) definition of occupation, we suggest that when something becomes an addiction it likewise shapes individuals' identities, habits, roles, routines and values; it impacts personal causation by affecting self-efficacy and mastery (Wasmuth, Outcalt, Buck, Leonhardt, Vohs, \& Lysaker, 2015) while shaping and being shaped by the environment. We introduce the concept of 'addiction-as-occupation' to reflect that when something becomes an addiction, it also becomes a central occupation, albeit a harmful one (Wasmuth, Crabtree, \& Scott, 2014).

The notion that occupations shape identity and impact wellness is an important theoretical element to the concept of addiction-as-occupation. Proposing a relationship between occupation, identity, and well-being, Christiansen (1999) argued that identity is central to occupational function in social settings because it provides individuals with a personal context and understanding of their lives. If "acceptable," that identity contributes to a coherent self and the experience of well-being. In contrast, many have noted how identity disturbances characterize mental illnesses (Lysaker \& Lysaker, 2002), with some observing how identity significantly contributes both to continued participation in an addiction and the ability to remain abstinent in addiction recovery (Walters, 1996). However, drawing on Christiansen, if identities are constituted through experience and social interaction, it is reasonable to assume that engaging in new occupations and social relationships might support the development of new identities. 
Adopting the concept of addiction-as-occupation, this paper further explores if and how behaviors that are addictions shape identities, and impact well-being and to what extent those identities are adaptable.

\section{Defining Addiction}

Evolving definitions and changes in diagnostic criteria make it difficult to operationalize the term addiction. The current Diagnostic and Statistical Manual of Mental Disorders, Fifth Edition (DSM-5) eliminates the distinction between substance use, abuse, and dependence, listing criteria for substance use disorders and addictive behaviors under the heading "substance related and addictive disorders" (American Psychiatric Association, 2013), with non-drug related behaviors such as gambling now included in the spectrum of addictive behaviors (American Psychiatric Association, 2013). In addition, the wide range of 12-step programs for addiction recovery such as Overeaters Anonymous and Sex and Love Addicts Anonymous, along with functional magnetic resonance imaging (fMRI) studies of the commonalities between drug use and other addictive behaviors (e.g. Goudriaan, De Ruiter, Van Den Brink, Oosterlaan, \& Veltman, 2010), indicate that problems of addiction apply to more than just the over-use of 'harmful' substances. Drawing on DSM-5 criteria, addiction in this paper connotes compulsive and problematic engagement in an occupation. However, with definitions of addiction expanding to non-drug-related occupations such as eating and love, an important area of inquiry becomes the study of what makes some occupations 'addictions' - specifically, what makes some occupations harmful?

While DSM criteria and neurobiological research provide some guidelines, ambiguities remain. For instance, while it is well known that abuse of drugs can cause changes to the dopaminergic midbrain circuitry, these changes do not universally result in pathological 
behavior; in chronic pain management, for example, neuro-physiological changes produced by

opioids facilitate rather than impede occupational participation (Keane \& Hamill, 2010). Further research is needed to better understand how and when an occupation becomes problematic and/or harmful, and to begin to link occupations experienced as problems to known neurobiological markers of addiction. Through the lens of addiction-as-occupation, this paper explores individuals' experiences of addiction to contribute to this need.

\section{Addiction-as-Occupation}

Sackman, Sackman, and DeAngelis (1978) first suggested that heroin addiction could be viewed as an occupation (in the vocational sense) and that persons who enter addiction treatment should be viewed as out of work. More recently, an integrative and interpretative literature synthesis suggested that both impulse-control disorders and addictions provide meaning and organize individual's lives and could thus be considered occupations, warranting "a deeper exploration of occupational patterns and performance and the influence of context" (Kiepek \& Magalhães, 2011, p. 254). Harmful occupations, or those that are "disrupted, deviant, or selfdamaging" (such as addictions), have also been identified as important foci for documentation and additional research (Pierce, 2012, p. 5).

Exploration of the concept of addiction-as-occupation and its relationship to well-being (or lack thereof) might draw on the concept of occupational balance, which characterizes how occupations can facilitate health and well-being or cause harm (e.g., Backman, 2004; Stamm et al., 2009; Wilcock et al., 1997), since addictions generally interfere with the balance of traditional occupational roles, responsibilities, and routines (American Psychiatric Association, 2013). As other occupations diminish, the addiction may require more and more time and energy and have increasing influence in an individual's life (Moyers, 1997). Additionally, studies have 
demonstrated that addictive behaviors are more common in individuals experiencing barriers to participation in other occupations (e.g., Alexan-der, 2008). Likewise, Correia, Benson, and Carey (2005) found that higher levels of occupational participation correlate with decreased substance use in early recovery from addiction. Addictions, therefore, may be more likely to serve as occupations when other avenues to occupation are blocked.

Animal model studies of addiction also illustrate the inter-relationships between addiction and occupation. Over 30 years ago, Alexander and Hadaway (1982) showed that rats in normal laboratory conditions became addicted to morphine (compulsively ingesting it at the expense of ingesting food and water) whereas rats in environments that included running wheels for exercise, mulch for burrowing in, and the presence of other rats did not. Perhaps most compelling was that rats already addicted to morphine changed their behavior when placed in the enriched 'rat park', suggesting that opportunities for other 'occupations' could potentially reverse addictive behavior. Environmental enrichment has more recently been found to reverse cocaine addiction in mice (Solinas, Chauvet, Thiriet, El Rawas, \& Jaber, 2008), and removal of an enriched environment has been shown to predict return to drug addiction (Nader et al., 2014). Such findings echo Christiansen's (1999) notion that social interaction and participation in occupations can influence larger aspects of self which can then in turn impact behaviors and wellness. These animal model studies illustrate the extent to which opportunities for social interaction and occupational participation (or lack thereof) may contribute to addictive behavior.

The progression of addiction has been described as "often accompanied by a concurrent disaffiliation from the society at large and an increasing enmeshment in the culture of addiction ... [which] touches and transforms every dimension of one's existence" (White, 1996, p. xxiii). Addiction can thus be experienced as an all-encompassing lifestyle in which individuals adopt 
and enact various roles; they adopt a 'tribe' involved in similar occupations with similar rituals and adopt roles within that tribe such as dealer, provider, and junkie (White, 1996). Wasmuth et al. (2014) lend weight to the idea that addictions create identities, roles, habits, and routines, as does Gray's (2013) suggestion that addictions can provide a sense of fulfillment, ritual and certainty in individuals' lives. Within the occupational science literature, Helbig and McKay (2003) explicitly named addiction as "occupational in nature" (p. 144). Through the conceptual lens of addiction-as-occupation, addictive behaviors can be seen as attempts at self-organization, with emphasis given to the identities, roles, routines, and social organization patterns that emerge through engaging in an addiction.

\section{Veterans and Addiction-as-Occupation}

While addiction presents a significant public health concern (National Institute on Drug Abuse, 2012), substance related and addictive disorders affect veterans even more significantly. For instance, a recent study by Seal et al. (2011) suggested an addiction prevalence rate of 10\% for veterans versus $8 \%$ in the general population. Not only is the prevalence of addiction higher among veterans, but higher rates of co-morbidity with other mental illnesses compound the difficulties these veterans face (Ralevski, Gianoli, McCarthy, \& Petrakis, 2014). Dual-diagnoses among veterans contribute to high rates of homelessness (Ghose et al., 2013), infectious disease (Heslin, Guerrero, Mitchell, Afable, \& Dobalian, 2013), suicide (Ilgen et al., 2010), disability, and unemployment (Zivin, Pacz-kowski, \& Galea, 2011).

Although there has been exponential growth in addiction-related problems amongst veteran populations, studies suggest the effectiveness of addiction treatment services is quite low and high rates of relapse and treatment discontinuation have been reported (Laudet \& Humphreys, 2013). This suggests a need for a broader conceptualization of the problem of 
addiction and identification of alternative targets for intervention that take account of the social, cultural and environmental factors that lead to addiction (Blume, Rudisill, Hendricks, \& Santoya, 2013; Laudet \& Humphreys, 2013; Shaffer et al., 2004; Skewes \& Gonzalez, 2013). Building upon previous work by Wasmuth et al. (2014), this paper suggests that the concept of 'addictionas-occupation' can broaden understandings of addiction, supporting the development of more effective interventions.

In order to advance the construct of addiction-as-occupation as a possible foundation for developing new knowledge and treatment strategies, additional information is needed. Considering the prevalence of addiction and related problems within the veteran population, the present study uses the concept of addiction-as-occupation to explore the problem of addiction in the lives of veterans, with the specific aim of examining how addictions emerge as occupations in the lives of veterans with substance-related and addictive disorders.

\section{Methods}

\section{Design}

While addictive behaviors are often deeply embedded in the occupational lives of individuals, addiction-as-occupation is not a prevalent discourse in professional literature. Grounded theory (Charmaz, 2014) provided an inductive method for constructing a theoretical framework of addiction-as-occupation grounded in empirical data. Inductive methods such as grounded theory are particularly useful for exploring new concepts that do not align with existing theories (Corbin \& Strauss, 2008). Further, grounded theory focuses on developing theoretical frameworks that involve psychosocial processes, and addiction-as-occupation may be best understood as a process that changes over time and is influenced by social context (Hood, 2007). 


\section{Recruitment, Sample \& Data Collection}

This study used existing data collected from a larger, long-term mixed methods project (Lysaker et al., 2014). The purpose of the larger study was to compare the life experiences of veterans with various mental health diagnoses. All procedures were approved by University and Veterans Affairs (VA) Institutional Review Boards. Fifty-eight veterans (three women and 55 men) were recruited for this study. While many of them had been diagnosed as having substance abuse or substance dependence, all fall under the new heading of substance related and addictive disorders and also identify as having an addiction to the occupation in question. Thus, while the data used to describe addiction may not conform to strict diagnostic categories from previous diagnostic manuals, they provide depictions of first-hand experiences of what is understood by these individuals as an addiction and which fall under the current DSM heading substance related and addictive disorders. Recruitment was performed at a VA residential treatment center. Veterans who had been abstinent (verified by random urine drug tests) from all substances including alcohol and had no medication changes or hospitalizations over the month prior to recruitment were included.

This study used data collected via the Indiana Psychiatric Illness Interview (IPII; Lysaker, Clements, Plascak-Hallberg, Knipscheer, \& Wright, 2002). The IPII is semi-structured and intentionally broad in order to obtain a personal account of salient, personal life experiences while introducing minimal content. Interviews were conducted face-to-face, audio recorded and transcribed for analysis. Grounded theory methodologists suggest that 30 to 50 persons are needed to identify a psychosocial process (Morse, 1994). Thus, 35 transcripts were randomly selected for grounded theory analysis, in the knowledge that more transcripts were available for analysis if needed to complete the theoretical framework. While an iterative interview/re- 
interview process was not possible due to the use of existing data, because the IPII elicited a spontaneous narrative of respondents' life history and challenges, ample data were available to develop the grounded theory. The initial selection of transcripts was found to provide robust data related to addictions-as-occupation and saturation was reached.

\section{Data analysis}

Data were analyzed using a four-step coding procedure outlined by Charmaz (2014). Initial coding of five transcripts was performed independently by a research scientist and a doctoral student, both of whom had advanced training in grounded theory methods. Each text unit, or meaningful and relevant phrase or point of fact, was assigned a code. The researchers noted recurring patterns in the codes and labeled these codes as emerging categories, writing indepth memos about them. Through discussion, consensus on six categories was reached. Each researcher then independently coded 10 additional transcripts, noting further evidence for the original six categories while remaining open to the modification of the existing categories and the emergence of new ones. Analyses based on these transcripts were discussed and the theoretical framework was modified as appropriate. During analysis, several of the category titles and descriptions changed, others were added and some were discarded, as is common in grounded theory development (Charmaz, 2014).

While the researchers considered all data contained in the transcripts, they were specifically attuned to data related to the research aim. They focused on the development of categories that examined how addictions emerged as occupations in the lives of participants, with particular attention to how addictions provided meaning, identities, roles, routines and habits. Charmaz (2014) refers to this process as focused coding. Once focused coding was complete, the researchers conducted axial coding, the examination of the dimensions and properties of the 
salient categories, and theoretical coding, the determination of how the categories related to one another, to construct a framework that described how addiction emerged as an occupation. To address the trustworthiness of the analytic process, the researchers immersed themselves in the data for a period of 2 months, used constant comparison methods and memoing, maintained an audit trail and sought guidance from a methodological expert who advised them throughout the process.

The initial and focused coding led to eight salient categories; initial use/orientation, using with others/being influenced, filling time, increasing engagement, enacting roles, being recognized, attempting change, and experiencing discord and defeat. The researchers expanded these categories by examining the characteristics that emerged from the data for each salient category, noting not only what was said but also how this data unfolded as a process in the context of participants' life stories. These categories were then temporally arranged into a fivestep theoretical process through which the behaviors to which individuals became addicted unfolded as occupations in their lives. Representative quotations were selected to provide greater descriptive and contextual detail of each theme. Any exceptions to the representative quotes were noted.

\section{Results}

\section{Being Initiated}

Like occupations in general, the occupations to which veterans became addicted were initiated in social contexts and began as behaviors introduced by parents, family, or friends. One participant described seeing " a lot of card playing, a lot of drinking, a lot of ... . I seen my cousin, I must've been about 6 or 7 when I used to watch him shoot drugs into his arm" in his childhood home. Other participants talked about being initiated into using substances to which 
they eventually became addicted as if they were following in their parents' footsteps, despite an early desire not to do so - a process reminiscent of children who claim they will never follow their parents into a vocation, only to find themselves doing similar work (e.g. Pinchot, Lewis, Weber, Rikkers, \& Chen, 2008). One participant explained:

But in turn, I did exactly what she [his mother] did, which was turn my back on my family, start drinking and doing drugs, stealing, lying, hurting people. Everything I didn't think I could do, I did .... I didn't 'get' addiction and alcoholism until I went through it myself.

Addictive substance use also provided social connections among the family and friends of the participants. Just as shared occupations provide interpersonal bonding, so too did the addictive use of substances by the participants. One participant described how drinking tied him to his alcoholic mother, explaining how he did not understand her alcoholism until he became addicted to alcohol himself:

I loved my mother even though I didn't really understand all of what she did ... I certainly didn't understand the alcohol. Until she started giving it to me. Then I understood ... and I guess in a way it was the only way that we could bond.

Some participants even described their involvement with addictive drugs as being like a family business involving shared work of using, procuring, and selling substances. For one participant, the family business involved his dad, mom, and uncle, and, eventually, himself:

My mom had started doing pills, and my dad was drinking real bad ... so uncle, he smoked weed and sold it. I remember he started giving me a bunch and I started selling it ... [my mom] knew I smoked weed, I smoked it with her. I supplied her with it.

Many of the participants were thus initiated into addictive behaviors in much the same way as sub-sequent generations of families enter the same trade; the children learn the trade from their families and then share the lifestyle that the trade offers them.

Of 35 participants, four that were addicted to drugs and alcohol described their use as a response to disappointment or isolation rather than as being initiated in social contexts. One 
noted "I had a real negative attitude toward the military because they weren't holding up their end of the bargain, so I just started doing the little drug stuff, and then more and more." Another initiated alcohol use in response to his wife leaving him, and two starting drinking and using drugs when they left the military and had "nothing else to do."

\section{Increasing Engagement}

After initiating engagement in the occupation to which they became addicted, all participants described how it became central in their lives. Substance use expanded beyond the social world of family and friends in which it was most often initiated, becoming more frequent and sometimes involving ingesting ever-increasing quantities. As engagement expanded, other occupational roles, routines, or responsibilities often diminished.

I started fooling around with crack cocaine. That was the worst enemy I ever ran into. 'Cause for many years I didn't think I was hooked, I just thought it was something I enjoyed doing. I was snorting and smoking because I liked the way it made me feel. I started realizing I was losing everything that was good to me. Everything I appreciated and cherished, including my new family ... . I lived for cocaine and liquor and women. It got to the point where I'd pay my bills, and the rest of the month didn't make no difference. Drinking smoking, getting high. There'd be times where I wouldn't even buy food ... . I was sick in my addiction, do or die. As long as I got that high. As long as I was doing what I wanted to do.

Conversely, others noted heightened engagement in the occupation to which they were addicted in the absence of other occupations, as seen in this veteran's description of how his alcohol use was tied to leaving the military and returning to civilian life:

And when I got back ... they just kinda said, ok just go back to your normal life, and I didn't know what to do. You know, so used to having somebody telling me what to do, so used to being on guard, and then just to switch it off like that ... Um, you know, I started drinking a lot.

Another participant described the relationship between idleness and substance use while in the military: 
I was trained up to the hilt, I have all kinds of cer-tifications, I was like a golden boy. I wasn't doing anything in Germany but sit around, and that's not good for me. I would go and drink because I didn't have anything to do all day.

For these veterans, addiction became a substitute for what military service could no longer offer them. Similarly, many participants explained how drug use initiated in social contexts then became heightened and central to their lives when those social contexts dissolved, or when opportunities to participate in occupations halted.

\section{Establishing an Identity}

As individuals increasingly engaged in the behaviors they would eventually describe as addictions, they began to note the establishment of a prominent identity with corresponding ways of behaving toward others and toward themselves. One participant noted:

It consumes me. My addiction consumes me, and I don't think about anybody else. It's just all about me, I don't care about what others think or what others are doing. It's just about me and how I can continue my high or whatever.

For all participants, an occupation or set of occupations became central to their lives and each participant described how other aspects of their identities, such as those obtained through work, concomitantly became less prominent: "Um, I didn't work for, there was about a 3 year period where I didn't work at all ... I'd go out and get some pills or cocaine or something. It was just the same pattern." They often at this stage began to describe the behavior as an addiction, and the behavior to which a participant was addicted became described as that which provided an organizing occupational identity. At this point in the process, the participants' routines and habits were defined by addictions, and their actions demonstrated a notable degree of what might be considered commitment to the addiction and its corresponding identity.

Participants obtained their identity through their actions. This was evident in that when circumstances prevented their actions (e.g. engagement in the addiction), those circumstances 
posed a considerable threat to the person's identity or sense of self. For instance, over one third of the participants described becoming suicidal when they tried or were forced to abstain from the behaviors to which they were addicted: "If it got to the point where I didn't have the money for drugs or couldn't get drugs, I just became rock bottom depressed, suicidal."

Additionally, the actions that gave rise to participants' identities were described as relatively 'automatic'. In other words, participants described repeated patters of 'doing' with little reflection and a seeming inability to adapt behaviors to avoid recurring negative consequences. For example, one noted "my drinking took off incredibly ... it was just out of control ... I really wasn't thinking about any long-term problems.” Acknowledging potential problems that did not deter the behaviors, another said, "I was using drugs at work, working with electricity. I could have hurt myself, the people I was working with. I didn't care about that, I just cared about getting high.” While one described how he "just started messing up in school and stuff because I was always drinking or high or something, " a further participant explained that he:

... didn't work at all. I'd go out and get some pills or cocaine or something, it was just the same pattern, you know. Using, drinking, depressed, suicidal, psychiatric ward. I'd get out, same thing. Drinking, using, you know, suicidal, psych ward ... I started taking suboxone [a medication to assist in opioid addiction recovery that combines buprenorphine (a partial opioid agonist) and naloxone (an opioid antagonist)] and he [the doctor] told me ... taking suboxone alone is not going to cure you of your addiction ... and I never got that, um ... so for about 7 months I was on suboxone, and I was doing good, I still wasn't working because I was having anxiety of going out ... and so I didn't work. I was staying on the suboxone, and I wasn't using pain pills, but ... I was still messing with the cocaine ... uh, and it ended up, like hanging out with the wrong people.

Many participants illustrated how their addictions contributed to their identities through their descriptions of themselves and/or how others saw them. One bluntly stated, "fortunately they see me as another alcoholic." Such identities were maintained despite the problems or harms that the behaviors brought. For example, one noted: 
If you were to ask me a question like, would I love to be able to drink and get high, I'd say yes. But I understand that I shouldn't drink or get high, because $99.9 \%$ of the time, bad things will happen, maybe not instantly, but over time. I'm the real alcoholic that they talk about, I'm the serious addict.

Another explained:

I guess they gotta deal with my bullshit, cause I start using. People around me have to deal with me, cause I owe money there, or borrow money there, or not go to work. All the stuff that goes with using, I suppose. Financially, I guess emotionally. It's kind of selfish.

Participants continued the behaviors to which they were addicted and through which they self-identified despite problematic consequences. As a result, many experienced discord with family, work, or friends, as described in the next section. However, it is worth noting that many participants reported the structuring of time and shaping of identity that addictions provided in a positive light. For example, one stated, "I really like to help people get drugs. I like to make other people happy, because I felt like I couldn't make [my wife] happy, so I'd make somebody happy." Another described the enjoyment that he found through engaging in his addiction and how central it was to his life: "I cannot see me living without marijuana. To me, marijuana was something I was going to do the rest of my life. I just loved getting stoned."

Despite the positive aspects of engaging in drug use and other occupations that became addictions, all participants described increasing life problems that eventually led to continued attempts to change their behavior. One of 35 participants reported successfully changing and described how that successful change occurred (see below). The majority of participants described ongoing experiences of defeat.

\section{Experiencing Discord and Defeat}

Data suggest that identities were established through habitual patterns of engaging in addiction(s), and thus that participants' identities were tightly linked to their actions. Without 
those actions, participants not only lacked purpose, direction, and occupations to organize a day, but also experienced a breakdown of self that may be experienced as threatening their ability to survive. For instance, as mentioned above, many viewed suicide as the solution to addictive behavior, as demonstrated in this participant's story of sex addiction:

I was so disgusted with myself, and I was still jacking off in jail in front of the guards, and I just wanted to stop. I just wanted to stop it. I didn't want to live that way. I didn't want to be that person. So I took my sheets and braided them, and hung it from a vent.

Facing the threat of a diminishing self, participants' stories generally reflected continued engagement in the addiction with little personal agency or freedom to adapt as desired. Many participants noted that familiarity with their own identities, rooted in addictive behavior, and an awareness of a need or desire to change did not necessarily help them change. Even if they were aware of the trouble-some consequences, they were unable to adapt: "I'm still the same, but I think I just know more of what I need to do, although I can't seem to be able to do it." Another described how his sense of enjoyment and meaning diminished when he tried to stop engaging in his addiction, and that this is what allowed him to see the importance of the addiction in his life in other words, it allowed him to recognize that the occupation in question was an addiction.

It sucks ... It's hard to explain to somebody that's never dealt with it. Lot of people look at it like you're just lazy, or don't feel like doing anything. So, I don't know. I never really knew I had it until I started trying to sober up. After so long, and being sober, I thought man, if I'm going to feel this bad, I might as well be drinking.

Participants' identities and lives were centered on their addictions, but they felt defeated because their lives brought ongoing discord. Participants reported feeling defeated both by their attempts to use successfully and their attempts to abstain. Neither scenario brought with it the ability to adaptively engage in the world in a way that was satisfactory. 


\section{Finding Other Occupations}

Many participants made adjustments to their life circumstances such as changing friends, location, or jobs in an attempt to abstain from engaging in an addiction. However, such changes rarely allowed participants to accomplish prolonged abstinence, perhaps because of the centrality that the addictive behavior had in shaping participants' social relation-ships, identities, and routines. One participant explained that after numerous cross-country moves, "I went bringing all my problems with me, I couldn't run from them." and

I go out to Portland, drove out there. Got a job right away, was doing pretty well. I met a real wealthy woman. And, uh, she let me live in this house that she had just bought, to fix it up for her, because she wanted to buy a house in San Francisco. So she's just like, here's the house. And she said, the only thing I don't want you to do is grow pot in here. And of course, that's what I did. I built a whole secret room in the basement ... and before long, I started using cocaine ... I was trading pot for drugs ... got involved with some people and went through treatment, um, then I got kicked out of that house and got an apartment on the other side of town and started my own business, and hired someone who had a heroin habit, and um, I started doing heroin. Walked right into it.

One of the challenges the participants encountered was that the behavioral patterns they used to move away from the occupation of addiction mirrored the occupational style of the addiction. For instance, one participant who moved repeatedly to find places to live and do drugs began to move frequently searching for friends who could provide more acceptable ways of filling his time. Another participant who used drugs to deal with the pain of divorce threw himself into his work and other relationships and occupations to avoid this pain. These attempts at change which mirrored addictive patterns rarely resulted in lasting modifications in behavior and/or identity.

In one instance, however, a participant changed the way in which he interacted, participated, or was recognized. Such changes in occupational patterns allowed him to overcome the identity he had assumed through his addiction: 
And in prison, for some reason, inmates turned to me, and asked my advice. And I guess the corrections officers noticed, and they pulled me to the side, and our program, we had some inmates run. And, of course, you get different perks if you run it. So I said sure, so I do that, I start running the classes, start sharing my experiences. What fascinated me was that they listened. They were actually paying attention. I actually became, I don't want to say a role model, but I had a lot of respect, and it wasn't from fighting or bullying, it was just from talking. I'd say talking helps a lot.

For this participant, finding new modes of engagement and interaction facilitated his ability to avoid returning to his addiction(s).

\section{Summary of Findings}

These results demonstrate the ways in which addictions develop as occupations for some individuals. As participants sought to find their place in the world and build an identity, they were influenced by factors such as familial and peer norms, social bonding and the surrounding culture. Most participants reported that these influences became incorporated into their burgeoning identity, affecting the ways in which they viewed themselves and the actions that they took. Understood broadly, a significant part of individuals' larger identities were their occupational selves. These selves served to regulate individuals' actions over time and to create routines in their lives. When a behavior took the form of an addiction, much of their lives become shaped by addiction to the extent that it might best be understood as an occupation that brings with it some occupational gains but also many problematic consequences.

Many of the participants in this study progressed from social exposure to an occupation such as drug use to beginning to engage in it addictively. As addiction became central to their lives, that occupation led to a firmly established identity rooted in engagement in the addiction(s). As these individuals experienced significant negative consequences and defeat, many of them continued to describe their identity as wrapped up in their addiction(s).

Participants' identities surrounding their addictions remained, even when other identities such as 
that of husband or bar back or active military member began to disintegrate, suggesting the centrality of the identities that emerged through engaging in addictions. While participants identified with and committed a degree of resources and energy to other identities, they began to focus more and more on their addiction(s). The occupations to which participants were addicted became their primary occupations and thus central to their self-understanding. Even when attempts were made to combat the addiction through a change of environment, profession, or social network, participants often found themselves returning to their addition(s) as they sought out meaning and organization in their new situations, illustrating the salience of addictions as occupations.

\section{Discussion}

Some key findings emerging from this study were that the occupations to which these participants were addicted provided some benefits such as opportunities for social connection, structuring of time, enjoyment, and the development of an identity. There were some problems, though, noted by nearly every participant, regarding the degree to which addictions satisfactorily met occupation needs on an ongoing basis. Participants reported their addictions as eventually disrupting social relationships, and as leading to a seeming inability to make behavioral adjustments. The occupations to which individuals were addicted became necessary to maintain their personal identities and existence, but also contributed to much conflict and distress, leading participants into frustrating life situations where they ultimately felt little agency or freedom.

Finally, the majority of participants attempted to eradicate engagement in their addiction, but often the things that they did to replace their addictions did not provide a lasting means for abstinence. This may suggest that the salience of identities developed through engaging in addictions results in a return to the addictive occupation despite changes in surroundings, jobs, or 
friends. However, a deeper exploration of this proposition is necessary and suggests an area for future study.

The one participant who reported sustaining abstinence from his addiction described how he became a role model amongst his peers and began to be recognized as someone who did not use. His new identity was paired with a responsibility to share his experiences to help others, potentially making this identity more robust. It is possible that this success aligns with the 12step programs, in which individuals are seen as in recovery, recognized for periods of sobriety or clean time, and encouraged to share their experiences regularly and on an ongoing basis (Tonigan, Connors, \& Miller, 2003). Other participants changed locations or other circumstances, but did not report being seen differently by themselves or by others.

Building upon previous work by Helbig and McKay (2003), Kiepek and Magalhães (2011) and Wasmuth et al. (2014), this study has further elucidated the construct of addiction-asoccupation. Addictions were found to occupy and organize time, create roles and routines, establish an identity and sense of self, and regulate interactions with other social systems, thereby meeting the definition of an occupation (Canadian Association of Occupational Therapists, 2014; Townsend, 1997; Yerxa, 2000). Conceptualizing addiction-as-occupation sheds light on the challenges of recovery by revealing recovery to be an entire restructuring of the individual's occupational life; it calls for opportunities to engage in new occupations geared specifically toward reshaping social lives, identities, habits, roles and routines. The findings suggest that recovery requires more than replacement occupations. Rather, health promoting occupations should provide individuals with the needed organization, social interconnection, and identity development while also fostering an increasing sense of freedom from addiction-related identities, roles, and habits. 
The concept of addiction-as-occupation advances understandings of humans as occupational beings who are significantly shaped and reshaped by the types of occupations in which they engage. A treatment model that centers on the need to rebuild occupational identities in addiction recovery underscores the impact that occupational engagement (and alterations in occupational engagement) can have on human biopsychosocial phenomena. It paves the way for further research that investigates how neurophysiology and other aspects of the human organism are changed through occupational engagement, and how healthy versus harmful occupations might be defined.

\section{Limitations}

Grounded theory often involves multiple stages of data collection, with researchers returning to participants to pose questions that more deeply explore emerging categories and themes. A limitation of this study was that it relied on extant data and participants could not be re-interviewed. However, the data set was extensive and comprehensive in nature, allowing for an iterative process where more data was always available for further exploration of categories and themes as they emerged throughout the analytic process. Additionally, the data were drawn from a select group of veterans receiving substance abuse treatment services through one location in one state in the US, limiting the transferability of these findings to groups with similar characteristics. The cross-sectional design is also a limitation, in that participants' views may have changed as they progressed through treatment.

Describing the importance of reflexivity in qualitative research, Finlay (2002) noted the importance of researchers finding ways to analyze how subjective and intersubjective elements influence their research" (p. 531). The authors brought a number of perspectives to this study, which likely contributed to the construction of data (as is typical in constructivist grounded 
theory; Charmaz, 2014). The first author is an occupational therapist, and both authors ascribe to the belief that human identity and experiences are fluid and changeable through occupational performance. Additionally, the authors have a shared interest in exploring addiction-asoccupation. In other words, they share the theoretical notion that the centrality of addiction in addicts' lives suggests it is an occupation. While researchers strictly followed grounded theory guidelines to ensure themes emerged from the data, special focus was given to data detailing how the occupations to which individuals were addicted shaped their lives. However, this influence was minimized in this study in that data collection interviews were intentionally broad and conducted by an individual who did not share the same theoretical background as the researchers and who was blind to the purposes of this study.

Finally, the data were based on self-reports. While self-reported experiences are the heart of grounded theory (Charmaz, 2014), they are also defined by those doing the reporting. No effort was made to confirm the factual accuracy of any events or to verify the ways in which the participants described their situations; however, with grounded theory's focus on the ways in which individuals construct their reality, it is their perspectives that are of paramount importance to the analysis (Charmaz, 2014). Nonetheless, it is acknowledged that interviews often obtain stories that are a joint construction between the interviewer and interviewee, shaped by the conversation that takes place (Gubrium \& Holstein, 2003).

\section{Conclusions}

Addiction followed an occupational process as it unfolded in these 35 veterans' lives, shaping their routines, roles, and behaviors. The perspective of addiction-as-occupation revealed how it organized the participants' interactions, created meaning in their lives, and occupied their time. Conceptualizing addiction-as-occupation suggests the importance of addressing 
individuals' needs by rebuilding their occupational identities and experiences in addiction recovery.

\section{Acknowledgements}

The authors would like to thank Dr. Claire Draucker of the Indiana University School of Nursing for her review of various versions of this manuscript and for her invaluable assistance in the methodological aspects of this study. 


\section{References}

Alexander, B.K. (2008). The globalisation of addiction: A study in poverty of the spirit. Oxford: Oxford University Press.

Alexander, B.K., \& Hadaway, P.F. (1982). Opiate addiction: The case for an adaptive orientation. Psychological Bulletin, 92(2), 367-387. doi: 10.1037/0033-2909.92.2.367

American Psychiatric Association. (2013). Diagnostic and statistical manual of mental disorders, (5th ed.). Arlington, VA: American Psychiatric Publishing.

Backman, C.L. (2004). Occupational balance: Exploring the relationships among daily occupations and their influence on well-being. Canadian Journal of Occupational Yherapy. Revue Canadienne d'Ergotherapie, 71(4), 202-209. doi:

$10.1177 / 000841740407100404$

Blume, A.W., Rudisill, D.M., Hendricks, S., \& Santoya, N. (2013). Disease model. In P. M. Miller (Ed.), Principles of addiction: Comprehensive addictive behaviors and disorders, volume 1 (pp. 71-76). San Diego, CA: Academic Press.

Canadian Association of Occupational Therapists. (2014). CAOT - Canadian Association of Occupational Therapists. Retrieved July 7, 2014, from https://www.caot.ca/default home.asp?pageid=2398

Charmaz, K. (2014). Constructing grounded theory (2nd ed.). Thousand Oaks, CA: Sage.

Christiansen, C. H. (1999). Defining lives: Occupation as identity: An essay on competence, coherence, and the creation of meaning. American Journal of Occupational Therapy, 53(6), 547-558. doi:10.5014/ajot.53.6.547

Corbin, J., \& Strauss, A.L. (Eds.). (2008). Basics of qualitative research: Techniques and procedures for developing grounded theory. Los Angeles, CA: SAGE. 
Correia, C.J., Benson, T.A., \& Carey, K.B. (2005). Decreased substance use following increases in alternative behaviors: A preliminary investigation. Addictive Behaviors, 30(1), 19-27.

Finlay, L. (2002). "Outing” the researcher: The provenance, process, and practice of reflexivity. Qualitative Health Research, 12(4), 531-545. doi:10.1177/104973202129120052

Ghose, T., Fiellin, D.A., Gordon, A.J., Metraux, S., Goetz, M.B., Blackstock, O., . . J Justice, A.C. (2013). Hazardous drinking and its association with homelessness among veterans in care. Drug and Alcohol Dependence, 132(1-2), 202-206. doi: 10.1016/j.drugalcdep.2013.02.004

Goudriaan, A. E., De Ruiter, M. B., Van Den Brink, W., Oosterlaan, J., \& Veltman, D. J. (2010). Brain activation patterns associated with cue reactivity and craving in abstinent problem gamblers, heavy smokers and healthy controls: An fMRI study. Addiction Biology, 15(4), 491-503. doi:10. 1111/j.1369-1600.2010.00242.x

Gray, R. (2013). Thinking about drugs and addiction. Retrieved May 28, 2014, from http://www.nlpco.com/library/health/thinking-about-drugs-andaddiction/\#axzz3A2RX4rGR

Gubrium, J. F., \& Holstein, J. A. (2003). From the individual inteview to the interview society. In J. F. Gubrium \& J. A. Holstein (Eds.), Postmodern interviewing (pp. 21-50). Thousand Oaks, CA: Sage.

Helbig, K., \& McKay, E. (2003). An exploration of addictive behaviors from an occupational perspective. Journal of Occupational Science, 10(3), 140-145. doi:10.1080/14427591.2003.9686521

Heslin, K.C., Guerrero, E.G., Mitchell, M.N., Afable, M.K., \& Dobalian, A. (2013). Explaining differences in hepatitis $\mathrm{C}$ between U.S. Veterans and nonveterans in treatment for 
substance abuse: Results from a regression decomposition. Substance Use \& Misuse, 48(10), 854-862. doi:10.3109/10826084.2013.808222

Hood, J.C. (2007). Orthodoxy vs. power: The defining traits of grounded theory. In A. Bryant \& K. Charmaz (Eds.), The sage handbook of grounded theory. Thousand Oaks, CA: SAGE. Ilgen, M.A., Burnette, M.L., Conner, K.R., Czyz, E., Murray, R., \& Chermack, S. (2010). The association between violence and lifetime suicidal thoughts and behaviors in individuals treated for substance use disorders. Addictive Behaviors, 35(2), 111-115. doi: 10.1016/j.addbeh.2009.09.010

Keane, H., \& Hamill, K. (2010). Variations in addiction: The molecular and the molar in neuroscience and pain medicine. BioSocieties, 5(1), 52-69. doi:10.1057/biosoc.2009.4

Kielhofner, G. (2008). Model of human occupation: Theory and application. Baltimore, MD: Lippincott Williams \& Wilkins.

Kiepek, N., \& Magalhães, L. (2011). Addictions and impulse-control disorders as occupation: A selected literature review and synthesis. Journal of Occupational Science, 18(3), 254276. doi: $10.1080 / 14427591.2011 .581628$

Laudet, A.B., \& Humphreys, K. (2013). Promoting recovery in an evolving policy context: What do we know and what do we need to know about recovery support services? Journal of Substance Abuse Treatment, 45(1), 126-133. doi: 10.1016/j.jsat.2013.01.009

Lysaker, P.H., Clements, C.A., Plascak-Hallberg, C.D., Knipscheer, S.J., \& Wright, D.E. (2002). Insight and personal narratives of illness in schizophrenia. Psychiatry: Interpersonal and Biological Processes, 65(3), 197-206. doi: 10.1521/psyc.65.3.197.20174 
Lysaker, P. H., \& Lysaker, J. T. (2002). Narrative structure in psychosis schizophrenia and disruptions in the dialogical self. Theory \& Psychology, 12, 207-220. doi:10.1177/0959354302012002630

Lysaker, P.H., Olesek, K., Buck, K., Leonhardt, B.L., Vohs, J., Ringer, J., . . Outcalt, J. (2014). Metacognitive mastery moderates the relationship of alexithymia with cluster $\mathrm{c}$ personality disorder traits in adults with substance use disorders. Addictive Behaviors, 39(3), 558-561. doi: 10.1016/j.addbeh.2013.11.007

Morse, J.M. (1994). Designing funded qualitative research. In N. K. Denzin \& Y. S. Lincoln (Eds.), Handbook of qualitative research (pp. 220-235). Thousand Oaks, CA: SAGE. Moyers, P.A. (1997). Occupational meanings and spirituality: The quest for sobriety. American Journal of Occupational Therapy, 51(3), 207-214.

Nader, J., Claudia, C., El Rawas, R., Favot, L., Jaber, M., Thiriet, N., \& Solinas, M. (2014). Loss of environmental enrichment increases vulnerability to cocaine addiction. Neuropsychopharmacology, 39(3), 780-780. doi: 10.1038/npp.2013.303

National Institute on Drug Abuse. (2011). Substance abuse among the military, veterans, and their families. Retrieved June 2, 2014, from http://www.drugabuse.gov/publications/topics-in-brief/substance-abuse-among-military$\underline{\text { veterans-their-families }}$

National Institute on Drug Abuse. (2012). Medical consequences of drug abuse. Retrieved June 1, 2014, from http://www.drugabuse.gov/related-topics/medical-consequences-drug$\underline{\text { abuse }}$

Pierce, D. (2012). Promise. Journal of Occupational Science, 19(4), 298-311. doi: $10.1080 / 14427591.2012 .667778$ 
Pinchot, S., Lewis, B. J., Weber, S. M., Rikkers, L. F., \& Chen, H. (2008). Are surgical progeny more likely to pursue a surgical career? Journal of Surgical Research, 147(2), 253-259. doi:10.1016/ j.jss.2008.03.002

Ralevski, E., Gianoli, M.O., McCarthy, E., \& Petrakis, I. (2014). Quality of life in Veterans with alcohol dependence and co-occurring mental illness. Addictive Behaviors, 39(2), 386391. doi: 10.1016/j.addbeh.2013.06.002

Sackman, B.S., Sackman, M.M., \& DeAngelis, G.G. (1978). Heroin addiction as an occupation: Traditional addicts and heroin-addicted polydrug users. International Journal of the Addictions, 13(3), 427-441.

Seal, K.H., Cohen, G., Waldrop, A., Cohen, B.E., Maguen, S., \& Ren, L. (2011). Substance use disorders in iraq and afghanistan veterans in va healthcare, 2001-2010: Implications for screening, diagnosis and treatment. Drug and Alcohol Dependence, 116(1-3), 93-101. doi: 10.1016/j.drugalcdep.2010.11.027

Shaffer, H.J., LaPlante, D.A., LaBrie, R.A., Kidman, R.C., Donato, A.N., \& Stanton, M.V. (2004). Toward a syndrome model of addiction: Multiple expressions, common etiology. Harvard Review of Psychiatry, 12(6), 367-374. doi: 10.1080/10673220490905705

Skewes, M.C., \& Gonzalez, V.M. (2013). Attitudes toward harm reduction and abstinence-only approaches to alcohol misuse among alaskan college students. International Journal Of Circumpolar Health, 72. doi: 10.3402/ijch.v72i0.21143

Solinas, M., Chauvet, C., Thiriet, N., El Rawas, R., \& Jaber, M. (2008). Reversal of cocaine addiction by environmental enrichment reversal of cocaine addiction by environmental enrichment. Proceedings of the National Academy of Sciences of the United States of America, 105(44), 17145-17150. 
Stamm, T., Lovelock, L., Stew, G., Nell, V., Smolen, J., Machold, K., . . Sadlo, G. (2009). I have a disease but I am not ill: A narrative study of occupational balance in people with rheumatoid arthritis. OTJR: Occupation, Participation and Health, 29(1), 32-39.

Tonigan, J. S., Connors, G. J., \& Miller, W. R. (2003). Participation and involvement in alcoholics anonymous. In T. F. Babor \& F. K. Del Boca (Eds.), Treatment matching in alcoholism: International research monographs in the addictions (pp. 184-204). New York, NY: Cambridge University Press.

Townsend, E. (1997). Enabling occupation: An occupational therapy perspective. Ottawa, Ontario: Canadian Association of Occupational Therapists.

Walters, G. D. (1996). Addiction and identity: Exploring the possibility of a relationship. Psychology of Addictive Behaviors, 10(1), 9-17. doi:10.1037/0893-164X.10.1.9

Wasmuth, S., Crabtree, J., \& Scott, P. (2014). Exploring addiction-as-occupation. British Journal of Occupational Therapy, 17(12), 605-613. doi:10. 4276/030802214X14176260335264

Wasmuth, S., Outcalt, J., Buck, K. D., Leonhardt, B. L., Vohs, J., \& Lysaker, P. H. (2015). Metacognition in persons with substance abuse: Findings and implications for occupational therapists. Canadian Journal of Occupational Therapy. doi:0008417414564865

White, W.L. (1996). Pathways: From the culture of addiction to the culture of recovery: A travel guide for addiction professionals (2nd ed.). Center City, MN: Hazelden Publishing.

Wilcock, A.A., Chelin, M., Hall, M., Hamley, N., Morrison, B., Scrivener, L., . . Treen, k. (1997). The relationship between occupational balance and health: A pilot study. Occupational Therapy International, 4(1), 17-30. doi:10.1002/oti.45 
Yerxa, E.J. (2000). Occupational science: A renaissance of service to humankind through knowledge. Occupational Therapy International, 7(2), 87-98. doi:10.1002/oti.109

Zivin, K., Paczkowski, M., \& Galea, S. (2011). Economic downturns and population mental health: Research findings, gaps, challenges and priorities. Psychological Medicine, 41(7), 1343-1348. doi: 10.1017/S003329171000173X 